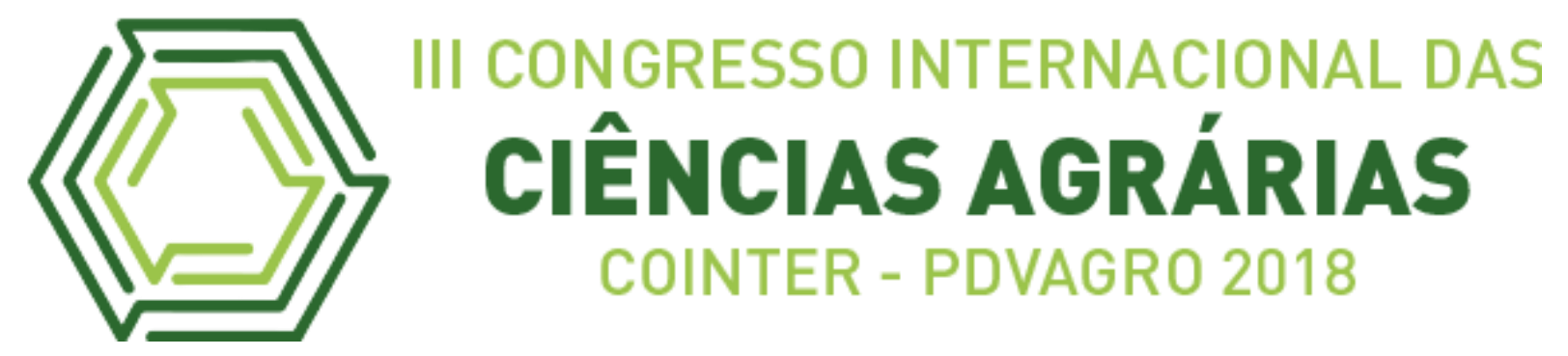

\title{
CONTRIBUIÇÕES DA DISCIPLINA DE CAPRINOVINOCULTURA NA FORMAÇÃ̂ DE TÉCNICOS EM AGROPECUÁRIA E ZOOTECNIA
}

\author{
Apresentação: Relato de Experiência \\ Tomaz Vicente da Silva ${ }^{1}$; Manuela Maria Santos e Silva ${ }^{2}$; Tiago Edvaldo Santos Silva ${ }^{3}$; \\ Marismênia de Siqueira Campos Moura ${ }^{4}$. \\ DOI: https://doi.org/10.31692/2526-7701.IIICOINTERPDVAGRO.2018.00723
}

\section{Introdução}

No IFPE- campus Vitória de Santo Antão a matéria de caprinocultura é um dos componentes curriculares ofertados nos cursos Técnicos em Agropecuária integrada ao Ensino Médio e no curso de Técnico de Zootecnia, na modalidade subsequente. O objetivo da disciplina é trabalhar conhecimentos práticos e teóricos com os estudantes, destacando-se conteúdos relacionados aos sistemas de criação, à importância sócio-econômica da atividade, conhecimentos básicos acerca do manejo sanitário, nutricional e reprodutivo, englobando manejo de matrizes em lactação, manejo específico de animais na fase de cria, recria, terminação, manejo de reprodutores, de matrizes, bem como o manejo pré e pós-parto..

Desta forma, esse trabalho objetiva relatar as contribuições da disciplina de caprinovinocultura na formação de técnicos/as em Agropecuária e de Técnicos/as Zootecnia do Instituto Federal de Educação, Ciência e Tecnologia de Pernambuco Campus Vitória de Santo Antão.

\section{Relato de Experiência}

No início da disciplina de caprinocultura ofertada ao IV período, em agosto de 2018, do curso integrado ao médio de agropecuária, percebeu-se um grande interesse da

\footnotetext{
${ }^{1}$ Estudante do curso técnico em agropecuária, IFPE, tomaz.vicete@gmail.com

${ }^{2}$ Estudante do Bacharelado em Agronomia, IFPE, manuelaifpe@gmail.com

${ }^{3}$ Agrônomo, AMA TERRA, tiagoedvaldo@hotmail.com

${ }^{4}$ Professora Dra , IFPE, marismenia.moura@vitoria.ifpe.edu.br
} 
turma pela disciplina, e identificação dos estudantes com a metodologia desenvolvida pela professora, o que facilitou a assimilação dos conteúdos. As aulas práticas foram uma metodologia constantemente utilizada, contemplando práticas de estação de monta dos ovinos, vermifugação, vacinação, extração de abscesso causado por linfadenite caseosa, casqueamento, acompanhamento de parto e pós parto, corte e cura do umbigo e descorna. Em cada uma dessas práticas respeitaram-se as normas do bem-estar animal.

As práticas foram sempre realizadas dialogando com os conteúdos lecionados em sala de aula, desde questões de manejo geral à exognosia (estudo do exterior dos animais domésticos) dos caprinos e ovinos.

A fim de contemplar as experiências de estudantes dos cursos de Agropecuária e Zootecnia com a disciplina, aplicamos um questionário online, com a pergunta aberta sobre a opinião dos estudantes acerca da disciplina de caprinovinocultura e sobre as contribuições para suas formações. Dentre as respostas, os estudantes evidenciaram a importância da disciplina para despertar o interesse pelo curso, até mesmo em se ver como empreendedores no ramo.

E de fato, a criação de caprino é uma produção de baixo custo, podendo ser usada pelo pequeno produtor para diversificar sua produção, como mais uma alternativa à geração de renda, não exige grandes áreas, é uma produção em que se podem utilizar todos seus produtos e subprodutos, vale salientar que o caprino por ser um animal ruminante, consegue um maior e melhor aproveitamento dos alimentos. E além da carne ser de sabor apreciado, também tem um excelente valor nutricional, com baixo teor de gordura.

Outras respostas contemplaram a importância da atividade para pensar, enquanto profissionais, no potencial produtivo de nossa região. Sendo a caprinovinocultura uma atividade em que os animais têm facilidade de adaptação a diferentes climas e pouco exigente quanto à alimentação. A caprinocultura vem se mostrando no agronegócio brasileiro como opção de diversificação da produção, assim gerando oportunidades de emprego, renda e possibilidade de manutenção do homem e da mulher com qualidade de vida no campo, o que demonstra seu importante papel no contexto da pecuária brasileira. 


\section{Considerações}

Após haver cursado a disciplina de caprinovinocultura, muitos estudantes que já tinham a vivência de campo, puderam agregar o conhecimento científico ao que já sabiam reconfigurando seus conhecimentos. E para outros, que têm em seus cursos, o primeiro contato com essa atividade produtiva, os conteúdos trabalhados em sala, sobretudo associados às práticas, impactaram positivamente a forma de enxergar a criação de caprinos e ovinos. E essa experiência possibilita que a partir desses conhecimentos, esses profissionais possam ter mais elementos para agir como agentes transformadores, por onde atuarem na vida profissional. Seja como produtores ou incentivando outras pessoas a enveredar pela produção ovina e caprina.

\section{Referências}

INSTITUTO FEDERAL DE CIÊNCIA EDUCAÇÃO E TECNOLOGIA DE PERNAMBUCO. Ementa da Disciplina de Caprinovinocultura do Curso Técnico em Agropecuária integrado ao médio e em Zootecnia Subsequente, Vitória de Santo Antão, s.d. 